\title{
Studies on the cuticle and musculature of freshwater mite, Unionicola aegyptiaca
}

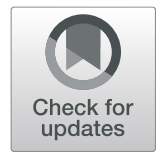

\author{
Somaia A. Ramadan, Tarek G. Ismail and Asmaa N. Mustafa (D)
}

\begin{abstract}
Background: The aquatic Acari are known as water mites and occupy a wide range of habitats. The freshwater mites, Unionicola aegyptiaca, were collected from the freshwater mussel, Caelatura aegyptiaca, River Nile, Sohag, Egypt. The present paper focuses on the structure of the cuticle and musculature of freshwater mite, U. aegyptiaca.

Results: Histologically, the cuticle consists of two main layers: epicuticle and procuticle. The latter divided into two sublayers, exocuticle (exo) and endocuticle (en). The musculature of the present species, U. aegyptiaca, is divided into three regions: gnathosoma, idiosoma, and legs. The muscles of the body are classified according to their position and function.

Conclusion: Details of muscles of gnathosoma, coxal epimerae, genital field, and legs were all described and discussed. The cuticle and musculature of $U$. aegyptiaca were studied by using the light microscope, and the drawings were down with the help of a camera Lucida. It is likely to note that the cuticle and musculature of freshwater mite, U. aegyptiaca, were described and discussed for the first time in Egypt.
\end{abstract}

Keywords: Water mites, Unionicola, Cuticle, Musculature

\section{Background}

The structure of the cuticular layers of mites has been studied by several authors (Grandjean, 1951; Woodring and Cook, 1962; Sannasi and Oliver, 1971; Tarba and Semenova, 1976; Pugh et al., 1987; Smrž, 1989; Iordansky and Stein-Margolina, 1993; Smrž, 2005). The cuticle of mites consists of two layers: epicuticle and procuticle, which is divided into exocuticle and endocuticle (Sannasi and Oliver, 1971; Bereiter-Hahn et al., 1984; Lindquist et al., 1996; Smrž, 2005). The cuticle of mites has to be sufficiently permeable to allow gas exchange but impermeable enough to prevent water loss (Haldane, 1927 cited in Colloff, 2009). Also, it varies in thickness, hardness, composition, and elasticity regarding different parts of the body and different species, in order to provide both mechanical protection and sufficient flexibility for locomotion (Haldane, 1927 cited in Colloff, 2009). Pritchard et al. (2015) reported that the sclerotized cuticle of mites can be identified by a brown/ yellowish area which often covers the whole of the outer adult body.

\footnotetext{
* Correspondence: a_n_19888@yahoo.com

Zoology Department, Faculty of Science, Sohag University, P.O. Box: 82524, Sohag, Egypt
}

During the nineteenth and twentieth centuries, musculature of invertebrates has been traditionally studied using light and electron microscopy (Chetverikov, 2014). The musculature of Acari is striated, and a complex skeletal musculature is involved regarding the movements of the various appendages. Both external and internal types of muscles are found in mites (Dhooria, 2016). Mitchell $(1955,1962)$ studied the musculature of aquatic mites, Unionicola fossulata, Najadicola ingens, and Blankaartia ascoscutellaris. Mitchell (1955) reported that the musculature of water mites is separated according to its function into three groups: dorsoventral muscles, supportive muscles, and coxal muscles. Also, Treat (1965) and Chetverikov (2014) studied the genital musculature of the female mites, Dicrocheles phalaenodectes, Loboquintus subsquamatus, and Trisetacus cf bagdasariani.

The present work aims to study the anatomical structures of the cuticle and musculature of freshwater mite, $U$. aegyptiaca, by using a light microscope.

\section{Materials and methods}

In the present paper, the freshwater mussels, Caelatura aegyptiaca, were collected from a small stream like a bay 
branched from the Nile River about $1 \mathrm{~km}$ east of Girga city $\left(26^{\circ} 21^{\prime} \mathrm{N}\right.$ and $\left.31^{\circ} 53^{\prime} \mathrm{E}\right)$, Sohag Governorate. The specimens of freshwater mites, Unionicola aegyptiaca, were collected from the freshwater mussels.

\section{A: for the cuticle study}

About 25 individuals of adult female freshwater mites, Unionicola aegyptiaca, were fixed with Carnoy's fluid, dehydrated in a graded series of alcohols, embedded in paraffin wax, sectioned at $3-5 \mu \mathrm{m}$, and stained with hematoxylin and eosin.

\section{B: for the musculature study}

About 30 individual adult females of the present species were preserved in clove oil about $30 \mathrm{~min}$ for clearing and then mounted in a droplet of Hoyer's medium. The mounted specimens were heated, until the appearance of air bubbles, to stretch safely the specimen under the weight of the slip cover.

The mounted slides were kept in trays in an oven at $35^{\circ} \mathrm{C}$ for $48 \mathrm{~h}$ for drying. The slides were photographed using a Canon digital camera attached to a light microscope. The musculature of three regions, gnathosoma (mouth parts), idiosoma, and legs, were drawn out from whole mounted specimens using a camera Lucida.

\section{Identification}

It is likely to note that the present species, Unionicola aegyptiaca, was identified and described as a new species by Ramadan et al. (2015). The mussel, Caelatura aegyptiaca, was described by Van Damme (1984) and Ibrahim et al. (1999).

The terminology and abbreviations of the cuticular layers and muscle groups of the present species are developed by Mitchell (1955), Alberti et al. (1981), and Alberti and Coons (1999).

\section{Results}

The cuticle

The cuticle of the present freshwater mite Unionicola aegyptiaca lacks any markings or structural modifications. No cell walls or other histological structure is demonstrable in the cuticular layers. The cuticle of the present species consists of two main layers: epicuticle and procuticle. Histologically, the epicuticle layer has a conspicuous yellowish green color while differential basophilia was recorded among the procuticle layer (Pl. 1a). The procuticle is characterized by fine striation and divided into two sublayers exocuticle (exo) and endocuticle (en) (Pl. 1a, d, e). Generally, each exocuticle and endocuticle sublayers are divided into two regions (exo1 and exo2, and en1 and en2, respectively). The examination of the histological sections through the $\mathrm{cu}$ ticle revealed that the thickness and number of cuticular layers vary according to the body region of the present species (Pl. 1a-g). Histologically, the epidermis appears as cuboidal cells with densely stained nuclei.

\section{The musculature}

The body of freshwater mite, Unionicola aegyptiaca, consists of five segments of palps (p1-p5), chelicerae (main shaft and two movable digits), two groups of coxal epimerae (I-IV), genital field (a pair of dorsoventral plate and a pair of ventral plates) and legs (Fig. 1a).

The musculature of the present species, Unionicola aegyptiaca, is divided into three regions: gnathosoma (mouth parts), idiosoma, and legs. Moreover, these muscles can be classified according to their position to the body and their function. According to their position of the body, the gnathosomal region includes the muscles of gnathosomal base (capitulum), chelicerae, palpi, and hypostome. The idiosomal region includes muscles of the coxal epimerae and genital field. According to the function of muscles, the gnathosomal region includes elevators, depressors, flexors, and hypostomal muscles. The idiosomal region includes dorsoventral, supportive, coxal (elevators and depressors), and genital muscles, while the leg segments include protractor, retractor, flexors, and elevator muscles. As a result of bilateral symmetry, the present work will describe the musculature of the right side of the body.

\section{Muscles of gnathosomal region}

The origin and insertion of the muscles in the gnathosomal region are illustrated in Table 1. The gnathosomal base and cheliceral shaft regions are supported by seven (4 elevators and 3 depressors) and six (3 elevators and 3 depressors) muscles, respectively (Fig. 1b). The palpal segments are supported by four flexor (fl2-fl5) muscles. The flexor muscles consist of several number of bands ranging from 3 to 8 bands (Fig. 1c). The hypostomal muscles are originated from the cheliceral muscles and inserted into the anterodorsal margin of coxal epimerae III (Fig. 2a).

\section{The muscles of the idiosomal region}

The origin and insertion of the dorsoventral muscles are connected with the body wall. The supportive muscles are originated from different areas (the body wall, coxae, and genital field) and inserted into the transverse coxal ligament (Table 2), while the coxal muscles are originated from the coxal epimerae and inserted into the first segment of the legs (Table 2). The genital field contains three pairs of genital plate muscles: dorsoventral, ventral, and valval muscles. The origin and insertion of genital muscles are illustrared in (Table 2). The drawings of the idiosomal muscles are shown in (Fig. 2a, b). 

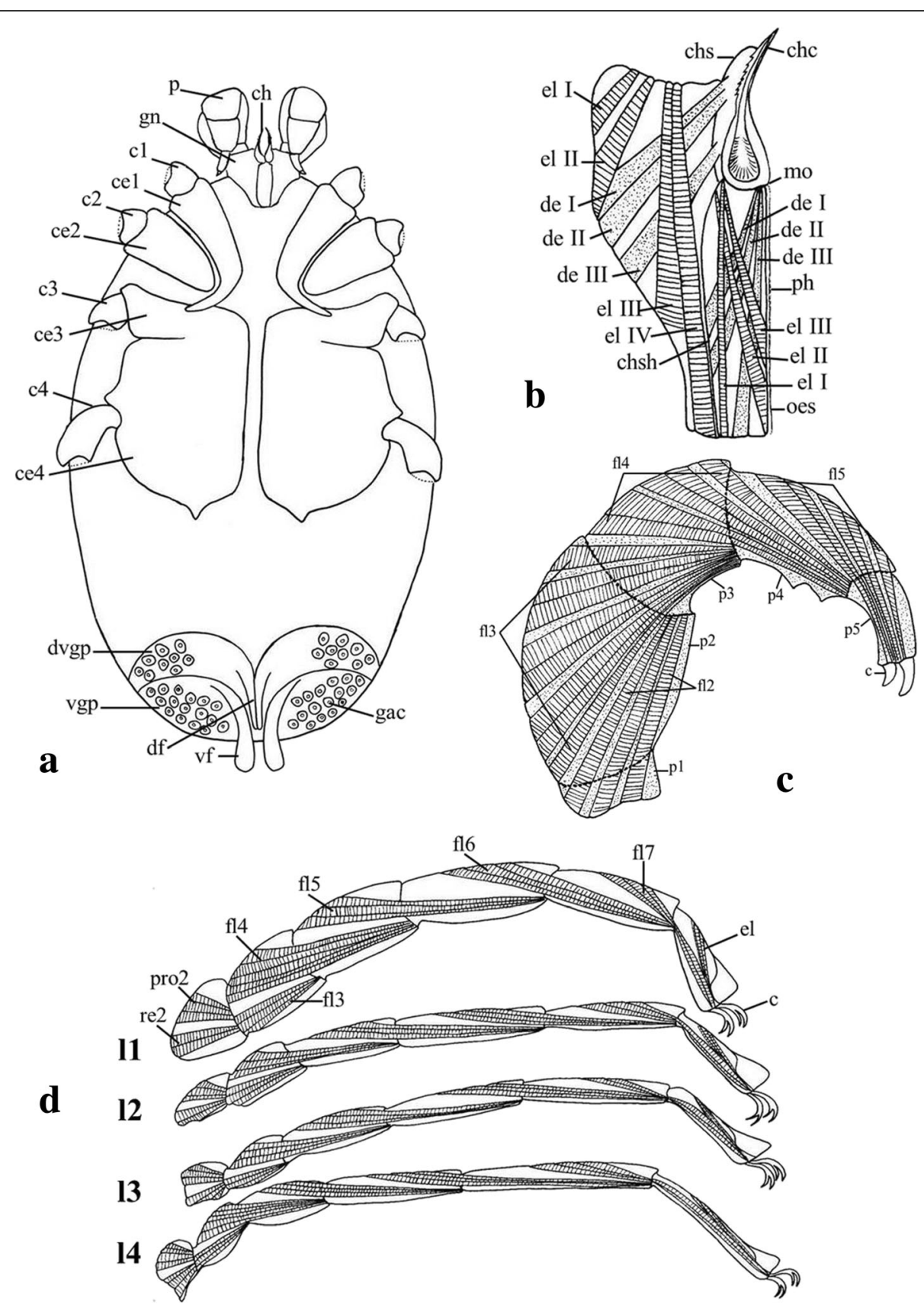

Fig. 1 Diagrammatic drawings of the adult female Unionicola aegyptiaca showing a structure of the ventral body, $\mathbf{b}$ gnathosomal base and cheliceral muscles, c palpal muscles, and $\mathbf{d}$ leg muscles

\section{Leg muscles}

The segments of legs (11-14) of the freshwater mite, Unionicola aegyptiaca, are supported by protractor (pr2), retractor (re2), five flexor (fl3-fl7), and elevator (el) striated muscles (Fig. 1d). The tarsus of each leg is supported by elevators muscles which are responsible for the claw elevation (Table 3). The previous muscles include several number of bands ranged from 2 to 5 in all legs (Pl. 1h).

\section{Discussion}

\section{The cuticle}

The present results showed that the cuticle of freshwater mite, Unionicola aegyptiaca, consists of two main layers: epicuticle and procuticle. Also, the procuticle layer is divided into two sublayers: exocuticle and endocuticle. Each of the previous sublayer divided into two regions (exo1 and exo2, and en1 and en2, respectively). Similar results were recorded by Sannasi and Oliver (1971) and 

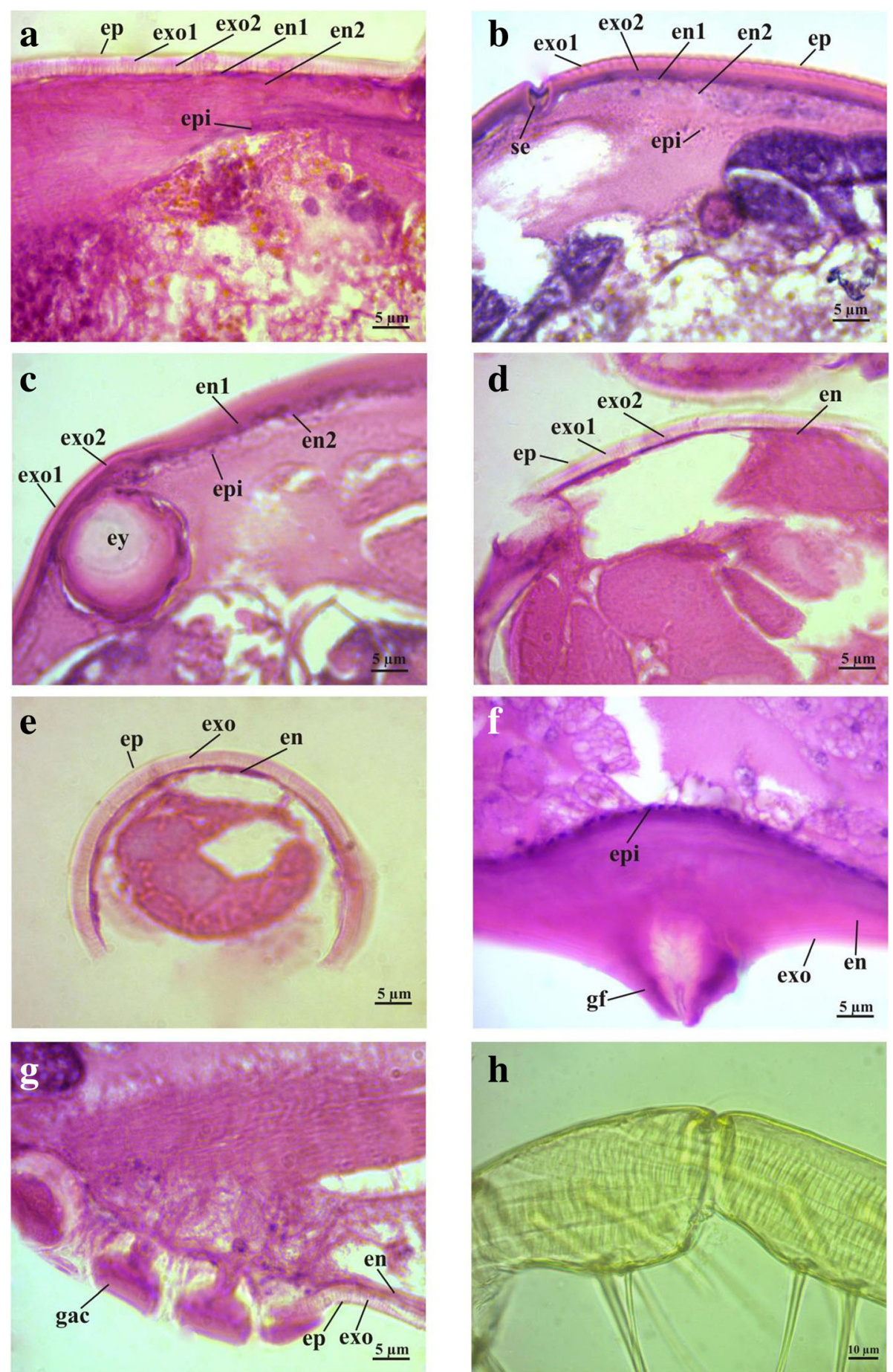

Plate $1 \mathbf{a}$ - $\mathbf{g}$ Photomicrographs of histological sections of adult female Unionicola aegyptiaca showing the cuticular layers of $\mathbf{a}$ body wall, $\mathbf{b}$ around the seta, $\mathbf{c}$ around the eyes, $\mathbf{d}$ palpal segments, e leg, $\mathbf{f}$ around genital flaps, and $\mathbf{g}$ between genital acetabulae. $\mathbf{h}$ Photograph of leg muscles of adult female Unionicola aegyptiaca

Smrž (2005) on some mite species such as Dinothrombium giganteum, Rhysotritia duplicata, Steganacarus striculus, Steganacarus magnus, Phthiracarus sp., and Tropacarus carinatus. Also, Smrž (2005) reported the same structure of the cuticle on the nymphal stages of some mite species such as Hermannia gibba, Tectocepheus velatus, Scutovertex minutus, Achipteria coleoptrata, and Eupelops occultus.

In the present data, the epidermis appears as cuboidal cells with densely stained nuclei. Similar data were found 
Table 1 The origin and insertion of the gnathosomal muscles of adult female Unionicola aegyptiaca

\begin{tabular}{|c|c|c|}
\hline \multirow[t]{2}{*}{ Muscle } & \multicolumn{2}{|l|}{ Gnathosomal base muscles } \\
\hline & Origin & Insertion \\
\hline Elevators I, II & First segment of palp & Body wall \\
\hline Elevators III, IV & First segment of palp & Hypostomal muscles \\
\hline \multirow[t]{3}{*}{ Depressors I, II, III } & Cheliceral sheath & Body wall and coxal epimerae \\
\hline & Cheliceral muscles & \\
\hline & Origin & Insertion \\
\hline Elevator I & Ventral wall of cheliceral shaft & Dorsally, base of the claw \\
\hline Elevators II, III & Lateral wall of cheliceral shaft & Dorsally, base of the claw \\
\hline Depressor I, II & Lateral wall of cheliceral shaft & Ventrally, base of the claw \\
\hline \multirow[t]{3}{*}{ Depressor III } & Ventral wall of cheliceral shaft & Ventrally, base of the claw \\
\hline & Palpal muscles & \\
\hline & Origin & Insertion \\
\hline Flexor 2 & Segment 1 (3 bands) & Segment 2 \\
\hline Flexor 3 & Segment 2 (8 bands) & Segment 3 \\
\hline Flexor 4 & Segment 3 (5 bands) & Segment 4 \\
\hline \multirow[t]{4}{*}{ Flexor 5} & Segment 4 (5 bands) & Segment 5 \\
\hline & Hypostomal muscles & \\
\hline & Origin & Insertion \\
\hline & Cheliceral muscles & Coxal epimerae III \\
\hline
\end{tabular}

in the freshwater mite, Unionicola fossulata (Mitchell, 1955). Sannasi and Oliver (1971) suggested that the epidermal cells of the cuticle of mite, Dinothrombium giganteum, form a syncytium in the normal mite.

\section{The musculature}

The present investigation revealed that the musculature of the freshwater mite, Unionicola aegyptiaca, is divided into three regions: gnathosoma (mouth parts), idiosoma, and legs. Similar data were mentioned by Mitchell (1955, 1962) for other species of unionicolid mites, Unionicola fossulata and Najadicola ingens, and trombiculid mite, Blankaartia ascoscutellaris. Whitmoyer et al. (1972) and Lindquist et al. (1996) distinguished the musculature in eriophyoid mites into three groups: skeletal, peripheral, and visceral muscles. They said that the skeletal muscles include gnathosomal, dorsoventral, genital and anal regions, and legs.

In each side of the body, the gnathosomal base and cheliceral shaft regions of the present species, $U$. aegyptiaca, are supported by seven (4 elevators and 3 depressors) and six (3 elevators and 3 depressors) muscles, respectively. The present author suggested that the contraction of the cheliceral muscles is responsible for the elevation and depression of the cheliceral claw. Similar data was reported by Mitchell (1955) for the freshwater mites, Unionicola fossulata and Najadicola ingens. The cheliceral shaft of Blankaartia ascoscutellaris consists of three elevators, two depressors, and two protractor muscles (Mitchell, 1962).

The palpal segments of the present species $U$. aegyptiaca are supported by four flexor muscles which contain 3 to 8 bands. The palpal segments of Unionicola fossulata and Najadicola ingens are supported by three flexors which include two muscles and two bands (Mitchell, 1955). The palpal segments of Blankaartia ascoscutellaris consist of three elevators, two depressors, three flexors, and three adductors muscles (Mitchell, 1962).

Also, the origin and insertion of the cheliceral and palpal muscles of $U$. aegyptiaca are similar to those of Unionicola fossulata and Najadicola ingens (Mitchell, 1955). Chetverikov (2014) showed that the gnathosomal muscles (cheliceral muscles and extrinsic muscles of palps) and opisthosomal muscles of Loboquintus mites are attached to the three posterior depressions near the prodorsal shield margin.

The present data showed that the idiosomal region of the present species includes dorsoventral, supportive, coxal (elevators and depressors), and genital muscles. Similar results were mentioned by Mitchell (1955) for other species of freshwater mites such as Unionicola fossulata and Najadicola ingens. Mitchell (1962) reported that the different body regions of Blankaartia ascoscutellaris include dorsal, dorsoventral, ventral, coxal (elevators and depressors), genital field, and excretory pore 


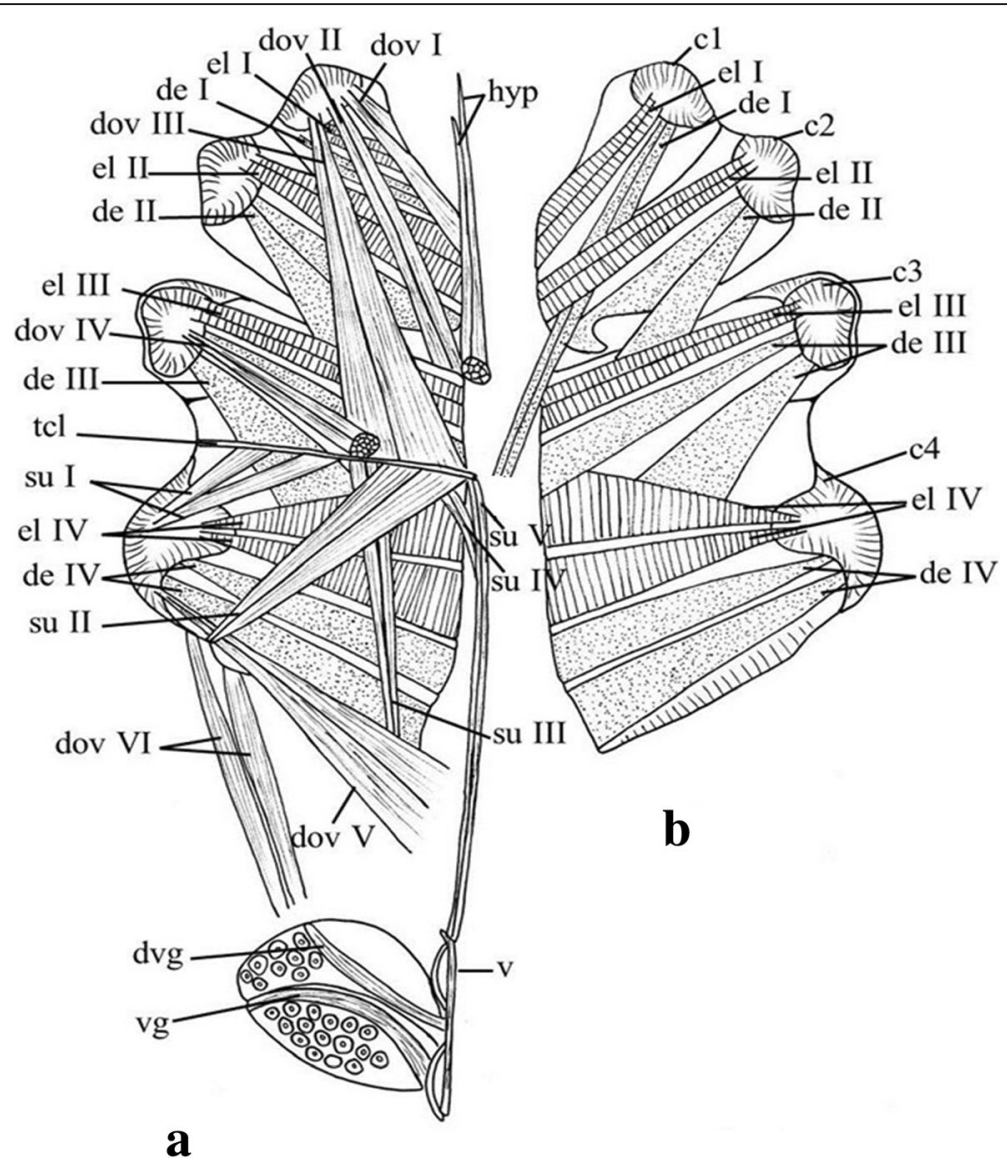

Fig. 2 Diagrammatic drawings of the adult female Unionicola aegyptiaca showing a dorsoventral, supportive, coxal, and genital muscles, and $\mathbf{b}$ coxal muscles after removing the other muscles

muscles. Treat (1965) studied the female genital muscles of moth ear mite, Dicrocheles phalaenodectes, and divided them into five anatomical groups: dorsoventral, lateral, ventral, epigynial, and endostylar.

The present work revealed that the right side of the idiosomal region of freshwater mite, $U$. aegyptiaca, had six and five dorsoventral and supportive muscles, respectively.

Mitchell (1955) studied the musculature of freshwater mite, Unionicola fossulata, and described seven dorsoventral and four supportive muscles. Mitchell (1962) reported seventeen dorsoventral, six dorsal, and eight ventral muscles for trombiculid mite, Blankaartia ascoscutellaris.

There are some similarities and differences in the number, origin, and insertion of the dorsoventral and supportive muscles between the present species, $U$. aegyptiaca, and the freshwater mite, Unionicola fossulata (Mitchell, 1955). In contrast to other Acari, the opisthosoma of eriophyoid mites is nearly free of dorsoventrsal muscles (Nuzzaci, 1976 and Shevchenko, 1983, 1986).
Shevchenko (1983, 1986) observed in Cecidophyopsis ribis a greater number of ventrolateral muscles in the first juvenile instar.

In the present work, the coxal muscles of $U$. aegyptiaca originated from the coxal epimerae and inserted into the first segment of the legs. These muscles are differentiated into four elevators and four depressors in all coxal epimerae. These results are in accordance with the coxal muscles of freshwater mites, Unionicola fossulata and Najadicola ingens (Mitchell, 1955), and trombiculid mites, Blankaartia ascoscutellaris (Mitchell, 1962). It is likely to note that the number of bands of elevators and depressor muscles on the coxal epimera is different in the present species compared with the previously published mite species (Mitchell, 1955, 1962).

The genital field of the present species, $U$. aegyptiaca, is supported by three pairs of genital plate muscles: dorsoventral, ventral, and valval muscles. In contrast, Mitchell (1955) illustrated two pairs of genital plate muscles for freshwater mite, $U$. fossulata. Also, the genital field of $B$. ascoscutellaris is associated with six pairs 
Table 2 The origin and insertion of dorsoventral muscles, supportive muscles, ventral (coxal) muscles, and genital muscles of adult female Unionicola aegyptiaca

\begin{tabular}{|c|c|c|}
\hline \multirow[t]{2}{*}{ Muscle } & \multicolumn{2}{|l|}{ Dorsoventral muscles } \\
\hline & Origin & Insertion \\
\hline । & Posterior margin of coxa I (2 bands) & Coxal epimerae I \\
\hline$\|$ & Posterior margin of coxa I (2 bands) & Coxal epimerae III \\
\hline III & Posterior margin of coxa I (2 bands) & Coxal epimerae IV \\
\hline IV & Posterior margin of coxa III (2 bands) & Coxal epimerae IV \\
\hline $\mathrm{V}, \mathrm{Vl}$ & Posterior margin of coxa IV (2 band) & Body wall posterior coxal epimerae IV \\
\hline \multirow[t]{2}{*}{ Muscle } & Supportive muscles & \\
\hline & Origin & Insertion \\
\hline I, II & Posterior margin of coxa IV (2 bands) & Transverse coxal ligament \\
\hline III & Posterior margin of coxal epimerae IV (2 band) & Transverse coxal ligament \\
\hline IV & Body wall ( 2 band) & Transverse coxal ligament \\
\hline V & Central genital field ( 2 band) & Transverse coxal ligament \\
\hline \multirow[t]{3}{*}{ Functional group } & Ventral (coxal) muscles & \\
\hline & Origin & Insertion \\
\hline & Leg 1 & \\
\hline Elevator I & Coxal epimerae I ( 2 band) & First segment of leg I (protractor) \\
\hline Depressor I & Body wall between coxal epimerae IV ( 2 band) & First segment of leg I (retractor) \\
\hline \multirow[t]{2}{*}{ Elevator II } & Leg $\|$ & \\
\hline & Coxal epimerae II (2 band) & First segment of leg II (protractor) \\
\hline Depressor ॥ & Coxal epimerae II (2 band) & First segment of leg II (retractor) \\
\hline \multirow[t]{2}{*}{ Elevator III } & Leg III & \\
\hline & Coxal epimerae III (2 band) & First segment of leg III (protractor) \\
\hline Depressor III & Coxal epimerae III (2 band) & First segment of leg III (retractor) \\
\hline \multirow[t]{2}{*}{ Elevator IV } & Leg IV & \\
\hline & Coxal epimerae IV (2 band) & First segment of leg IV (protractor) \\
\hline Depressor IV & Coxal epimerae IV (2 band) & First segment of leg IV (retractor) \\
\hline \multirow[t]{2}{*}{ Functional group } & Genital muscles & \\
\hline & Origin & Insertion \\
\hline Dorsoventral muscles & Dorsoventral plate & Dorsal flap \\
\hline Ventral muscles & Ventral plate & Ventral flap \\
\hline Valval muscles & Genital valve & Genital duct \\
\hline
\end{tabular}

Table 3 The origin and insertion of leg muscles of adult female Unionicola aegyptiaca

\begin{tabular}{lll}
\hline Muscle & Origin & Insertion \\
\hline Protractor 2 & Anterolateral wall, segment 1 & Base of segment 2 \\
Retractor 2 & Posterolateral wall, segment 1 & Base of segment 2 \\
Flexor 3 & Segment 2 & Base of segment 3 \\
Flexor 4 & Segment 2 & Base of segment 4 \\
Flexor 5 & Segment 3 & Base of segment 5 \\
Flexor 6 & Segment 4 & Base of segment 6 \\
Flexor 7 & Segment 5 & Base of claws \\
Elevator & Segment 6 & Base of claws \\
\hline
\end{tabular}

of genital plate muscles (Mitchell, 1962). In addition, the excretory pore of $B$. ascoscutellaris has five pairs of excretory muscles.

The leg segments (11-14) of the freshwater mite, Unionicola aegyptiaca, are supported by protractor (pr2), retractor (re2), five flexor (fl3-fl7), and elevator (el) muscles. Similar data are reported by Mitchell (1955, 1962) for the mites $U$. fossulata and B. ascoscutellaris. The number of leg muscle bands in $U$. aegyptiaca ranged from 2 to 5 in all legs, while the leg bands of $U$. fossulata ranged from 2 to 4 (Mitchell, 1955) and from 1 to 3 for B. ascoscutellaris (Mitchell, 1962). The origin and insertion of the leg muscles of $U$. aegyptiaca are 
similar to those of $U$. fossulata and $B$. ascoscutellaris (Mitchell, 1955, 1962, respectively). It is likely to note that the depressor muscles of leg tarsus were absent in $U$. aegyptiaca and $U$. fossulata (Mitchell, 1955) and present in B. ascoscutellaris (Mitchell, 1962).

\section{Conclusion}

The study of cuticle and musculature of freshwater mite, Unionicola aegyptiaca, was carried out for the first time in Egypt. The present work depends on the examination of the histological sections by using light microscope, while the drawings were carried out with the help of a camera Lucida. The cuticle consists of two main layers: epicuticle and procuticle. The musculature of the present species is divided into three regions: gnathosoma, idiosoma, and legs. Finally, the studies on the cuticle and musculature of the freshwater mites are few. So, more studies on them are required in the future.

\begin{abstract}
Abbreviations
c: Claw; C1-c4: Coxa I-IV; ce1-ce4: Coxal epimerae I-IV; ch: Chelicera; chc: Cheliceral claw; chs: Cheliceral sheath; chsh: Cheliceral shaft; de I-de IV: Depressors (I-IV); df: Dorsal flaps; dov I-dov IV: Dorsoventral muscles (I-VI); dvg: Dorsoventral genital muscles; dvgp: Dorsoventral genital plate; el: Elevator of leg tarsus; el I-el IV: Elevators (I-IV); en: Endocuticle; en1: First endocuticle; en2: Second endocuticle; ep: Epicuticle; epi: Epidermis; exo: Exocuticle; exo1: First exocuticle; exo2: Second exocuticle; ey: Eye; gac: Genital acetabulae; gf: Genital flaps; gn: Gnathosomal base; hyp: Hypostomal muscles; I1-|4: Legs I-IV; mo: Mouth opening; oes: Esophagus; p: Palp; p1: Palpal trochanter; p2: Palpal femur; p3: Palpal genu; p4: Palpal tibia; p5: Palpal tarsus; ph: Pharynx; fl2-fl7: Flexors (2-7); pro2: Protractor; re2: Retractor; se: Setal insertion; su I-su V: Supportive muscles (I-V); tcl: Transverse coxal ligament; v: Valval muscles; vf: Ventral flaps; vg: Ventral genital muscles; vgp: Ventral genital plate
\end{abstract}

\section{Acknowledgements}

Members of the Zoology Department, Fac. Sci., Sohag University

\section{Authors' contributions}

RSA was responsible for the points of research and writing and revision of the manuscript. TIG was responsible for writing and revision of the manuscript. MAN carried out the fieldwork as part of her doctorate research and wrote the first manuscript. All authors read and approved the final manuscript.

\section{Funding}

There is no funding for this study and it jointly funded by the authors.

\section{Availability of data and materials}

Not applicable.

\section{Ethics approval and consent to participate}

Not applicable.

\section{Consent for publication}

Not applicable.

\section{Competing interests}

The authors declare that they have no competing interests.
Received: 9 April 2019 Accepted: 22 October 2019

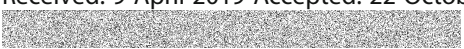

\section{References}

Alberti, G., \& Coons, L. B. (1999). Acari: Mites. In F. W. Harrison, \& R. Foelix (Eds.), F (eds): Microscopic anatomy of invertebrates, (vol. 8C, pp. 515-1215). Chichester: Chelicerate Arthropoda. Wiley and Sons.

Alberti, G., Storch, V., \& Renner, H. (1981). Über den feinstrukturellen Aufbau der Milbencuticula (Acari, Arachnida). Zool. Jb. Anat., 105, 183-236.

Bereiter-Hahn, J., Matosltsy, A. G., \& Richards, K. S. (Eds.) (1984). Biology of the integument. 1- Invertebrates, (p. 841). Berlin, Germany: Springer Verlag.

Chetverikov, P. E. (2014). Distal oviduct and genital chamber of eriophyoids (Acariformes, Eriophyoidea): refined terminology and remarks on CLSM technique for studying musculature of mites. Experimental and Applied Acarology, 64(4), 407-428.

Dhooria, M.S. (2016). Fundamentals of applied acarology. Springer 459 pp.

Grandjean, F. (1951). Sur le tegument des Oribates (2-serie). Bulletin du Museum nationale d'Histoire Naturelle, 23, 497-507.

Haldane, J. B. S. (1927). Physiology and internal anatomy. In: Colloff, M. J. (2009). Dust mites. 583 pp.

Ibrahim, A. M., Bishal, H. M., \& Khalil, M. T. (1999). Freshwater mollusks of EEAA. Publ. NBU, 10, 1-145.

Iordansky, S. N., \& Stein-margolina, V. A. (1993). The cuticle structure and xeroresistance of the deutonymph and adult oribatid mite Tectocepheus velatus (Acariformes, Oribatei). Zoologicheskii Zhurnal, 72, 30-42 (in Russian).

Lindquist, E. E., Sabelis, M. W., \& Bruin, J. (1996). Eriophyoid mites: their biology, natural enemies and control. Amsterdam, The Netherlands: Elsevier.

Mitchell, R. (1955). Anatomy, life history, and evolution of the mites parasitizing fresh-water mussels.

Mitchell, R. (1962). The musculature of a trombiculid mite, Blankaartia ascoscutellaris (Walch). Annals of the Entomological Society of America, 55(1), 106-119.

Nuzzaci, G. (1976). Contributo alla conoscenza dell' anatomia degli Acari Eriofidi. Entomologica, Bari, 12, 21-55.

Pritchard, J., Kuster, T., Sparagano, O., \& Tomley, F. (2015). Understanding the biology and control of the poultry red mite Dermanyssus gallinae: a review. Avian Pathology, 44(3), 143-153.

Pugh, P. J. A., King, P. E., \& Fordy, M. R. (1987). A comparison of the structure and function of the cerotegument in two species of Cryptostigmata (Acarina). Journal of natural history, 21, 603-616.

Ramadan, S. A., Ismail, T. G., \& Mustafa, A. N. (2015). A new species of parasitic water mite, Unionicola aegyptiaca (Acari: Unionicolidae) collected from fresh water mussel, Sohag, Egypt. Assiut University. Journal of Zoology, 44(1), 1-17.

Sannasi, A., \& Oliver, H. (1971). Integument of the Velvet-mite, Dinothrombium giganteum, and histopathological changes caused by the fungus Aspergillus flavus. Journal of Invertebrate Pathology, 17, 354-365.

Shevchenko, V. C. (1983). Reorganisation of opisthosomal musculature of eriophyid mites (Acariformes, Tetrapodili) in the course of postembryonic development. Entomol. Obozr., 62, 379-383 (in Russian).

Shevchenko, V. C. (1986). Musculature of tetrapodili (Acariformes) and the problem of their segmental structure. Entomol. Obozr., 65, 833-843 (in Russian).

Smrž, J. (1989). Internal anatomy of Hypochthonius rufulus (Acari: Oribatida). Journal of Morphology, 200, 215-230.

Smrž, J. (2005). Structure of the cuticle of some ptyctimine oribatids (Acari: Oribatida). European Journal of Entomology, 102, 89-95.

Tarba, Y. M., \& Semenova, L. M. (1976). Cuticle structure of the Oribatei in relation to their ecology. Pedobiologia, 16, 127-135.

Treat, A. E. (1965). The genital musculature of the female moth ear mite Dicrocheles phalaenodectes. Acarologia, 7(3), 420-429.

Van Damme, D. (1984). The freshwater Mollusca of North Africa, (pp. 52-54). Dordrecht: W. Junk Publishers.

Whitmoyer, R. E., Nault, L. R., \& Bradfute, O. E. (1972). Fine structure of Aceria tulipae (Acarina: Eriophyidae). Annals of the Entomological Society of America, 65(1), 201-215.

Woodring, J. P., \& Cook, E. F. (1962). The internal anatomy, reproductive physiology, and molting process of Ceratozetes cisalpinus (Acarina: Oribatei). Annals of the Entomological Society of America, 55, 164-181.

\section{Publisher's Note}

Springer Nature remains neutral with regard to jurisdictional claims in published maps and institutional affiliations. 